\title{
Changing Research Culture
}

Igor $\check{S}_{v a b}, M D, P b D$

Department of Family Medicine, University of Ljubljana, Ljubljana, Slovenia
Conflict of interest: none reported

\section{CORRESPONDING AUTHOR}

Igor Švab, MD, PhD

Department of Family Medicine

University of Ljubljana

Poljanski nasip 58

SI 1000 Ljubljana, Slovenia

igor.svab@mf.uni-lj.si

\begin{abstract}
Although there is general agreement that family medicine has a lot to offer to the health care system, the academic dimension is still not widely understood. There are two main reasons why family medicine needs to develop its scientific potential: to address the true nature of the discipline, and to help in its recognition. The academic establishment benefits from academic family medicine by gaining new questions that are necessary to be answered and by gaining new research approaches.

Many problems are encountered when introducing family medicine into the academic arena. Two main strategies for developing family medicine research can be identified. The first is to adapt to the existing structure of the academic world by claiming equal rights with the developed disciplines, collaborating with other university departments in their research projects, publishing articles in established journals, and participating in established faculty development programs. The other, more demanding, strategy is to introduce changes to the academic arena by developing specific research questions, by collaborating on research within family medicine, and by developing family medicine's own success criteria for academic excellence. The two approaches are not mutually exclusive.
\end{abstract}

The World Organization of Family Doctors plays an important role in supporting both approaches through its international affiliations and contacts with policy makers.

Ann Fam Med 2004;2(Suppl 2):S30-S34. DOI: 10.1370/afm.150.

\section{INTRODUCTION}

1 The importance of primary care and family medicine is widely recognized. Primary care has also been shown to be a core factor of costeffective, high-quality health care. The research done in past years has shown that health care systems based on primary health care have better outcomes. ${ }^{1}$ The importance of primary care is further reflected by the many declarations describing the importance of primary care that were accepted throughout the world.

Although there is agreement that family medicine has much to offer the health care system, the justifications for its academic dimensions are less clear. In many countries family medicine is still perceived as a nonacademic discipline that should concentrate mainly on the provision of health care and leave the academic career aside. In countries where family medicine has managed to establish itself as an academic discipline, the need for developing adequate education ${ }^{2}$ has usually been articulated more clearly than the need for specific research.

This article examines the contribution of research to family medicine, the contribution of family medicine to the research culture, and the strategies that have been successful in this development, especially in Europe.

\section{CONTRIBUTION OF RESEARCH TO FAMILY MEDICINE}

There are many reasons why family medicine needs to develop its scientific potential. ${ }^{3,4}$ The first is that the discipline itself is fertile ground for research questions. The mix of cases and the signs and symptoms of illness are broader than in other medical specialties. The discipline plays a key 
role in chronic illness and preventive management. The research approach of family medicine is also an important tool. By addressing its problems in a scientific manner, family medicine is able to answer its unique questions in a systematic way and provide answers that are relevant to the discipline. Family medicine requires its own body of knowledge and its own research methods, which are only beginning to be developed. On the other hand, by showing that it is able to develop good research proposals and to carry out even very complex projects, family medicine is recognized as a scientific discipline equal to others.

The future of family medicine increasingly requires physicians to understand research methods so they can interpret and apply research findings from family medicine or other disciplines to improve practice. It is no longer enough that family physicians are devoted and caring; they also need to become science and research oriented. This change in focus brings with it a range of challenges that will require introducing information systems into everyday practice, as well as managing an increased workload. Adding research to practice has enormous potential to increase quality of care, but doing so will require new resources.

\section{CONTRIBUTION OF FAMILY MEDICINE TO RESEARCH CULTURE}

It became obvious early on that family medicine makes a specific contribution to medicine as a science. ${ }^{5}$ It has much to offer to medicine in terms of approaches to research and the questions it is able to answer. ${ }^{6}$ The contribution of family medicine is shown by the its unique approach to solving the problems encountered in daily practice. ${ }^{7}$ Although practice does not have specific research methods, it is often the vehicle that has introduced innovative methods in medical research, often by applying to medical science the methods developed by other scientific disciplines. Adapting conventional research methods from other disciplines to the family medicine research enterprise was enhanced by a series of conferences held in Canada from 1989 to $1993 .^{8-12}$ Traditional single-practice research projects, ${ }^{13}$ developed by pioneers in family medicine, were later enriched by new developments. One important event was the introduction of qualitative methods to medicine. ${ }^{14-16}$ Another example of new research strategies has been the advent of practice-based research networks that, when combined with electronic health records, provide a laboratory for rapidly addressing certain types of clinical research issues. Large-scale multipractice trials allow the investigation of issues, such as mild hypertension in the elderly ${ }_{1}{ }^{17}$ that can be addressed only in a primary care setting.

\section{PROBLEMS}

Family medicine research does not address all relevant issues adequately or evenly. Progress is often slow; some countries have experienced a rapid development of family medicine research, while some others have not. ${ }^{18}$ It is interesting that the pace of development does not reflect the economic characteristics of a country but is a result of other factors. There are many reasons why the change in research culture does not happen as fast as it should.

Research is to a large extent a bottom-up process. Physicians are encouraged to approach their work in a scientific way, to open their practice for study projects, and to take up research. ${ }^{19}$ Nevertheless, it is still difficult to be a researcher in practice. There is often a lack of protected time, which is not always available for this activity, especially in countries where family medicine is just starting to develop as an academic discipline. Payment systems in some countries inhibit practice research by putting more emphasis on competition among physicians in a struggle for economic survival.

Although there are good organizations that support practice research, the top-down approach has not been successful. Family medicine has not succeeded in accessing policy makers and in ensuring adequate funds for practice research at an international level, nor has it been successful in developing an overall research agenda for practice at the more global level.

There are two elements in the development of research programs in family medicine. The creation of the clinician-researcher, a person who is paid to practice and conduct research, often comes to mind first, but a second element is equally important: the creation of interdisciplinary teams of researchers who support each other and provide adequate critical mass. Family medicine has not developed centers of excellence, such as those established by other clinical specialties. This lack in organizational support is due in part to the nature of practice, in which specialization and the reductionist approach are foreign to the culture and basis of practice, and to the nature of physicians, who have tended to work in isolation and depend upon their own skills and resources. Change management approaches, such as shown by John Oldham in the United Kingdom, draw on "practices of excellence" and subsequent diffusion of change through local champions and peer support as a suitable method. ${ }^{20,21}$ The problem with the development of an academic discipline is that it must remain in contact with the basics of the discipline if it wants to survive. Distancing the academic branch of the discipline from its foundation can be dangerous. It is equally dangerous for common practice not to recognize the importance of research. 
Reference databases, of which Index Medicus is the most important, are used for measuring research performance. In Index Medicus, "practice" is allocated to a summary category (medical) rather than appearing under its own specialty. Funding bodies emphasize categorical over general research.

\section{STRATEGIES FOR CHANGE}

Two main strategies for change can be identified (Table 1 ), and the 2 approaches are complementary.

\section{Adapting to the Existing Structure}

Adapting to the existing structure means that family medicine accepts the existing academic criteria and claims its position within the existing academic establishment.

The logical step is to claim equal rights with the other more developed specialties. Policy makers and the academic and medical establishment should be aware of all circumstances in which family medicine does not occupy a position equal to that of other disciplines.

Collaboration with other well-established university departments by joining their research projects is also a good example. Through cooperation, family medicine researchers learn how to participate and eventually run a research project.

Family medicine academics can also benefit by publishing articles that introduce a new perspective to a clinical topic in established journals of other specialties.

\section{Introducing Change}

The other, more demanding strategy is to examine the specifics of the discipline and use them to introduce changes to the academic arena. There are many examples where this strategy has been successful.

\section{Development of Specific Research Questions}

Over the years family medicine researchers have developed their own informal research agenda for family medicine. This agenda was influenced by the inevitable market forces that guide the research grants throughout the world. These forces have influenced family medicine research priorities in such a way that sometimes they did not reflect the specifics of the discipline.

\begin{tabular}{ll}
\hline Table 1. Changing Research Culture Summary Points \\
\hline $\begin{array}{l}\text { Adapting to the existing } \\
\text { structure }\end{array}$ & $\begin{array}{l}\text { Inform about inequal position of the } \\
\text { disipline } \\
\text { Collaborate with established disciplines } \\
\text { Publish within established journals }\end{array}$ \\
Introducing change & $\begin{array}{l}\text { Develop research agendas } \\
\text { Collaborate internationally } \\
\text { Develop own success criteria }\end{array}$ \\
\hline
\end{tabular}

Accordingly, the European Society of General Practice/ Family Medicine (ESGP/FM) (Wonca region Europe) decided to address this issue by developing a definition of family medicine. The long process of reexamining the position and role of the discipline resulted in a new definition of family medicine, which was launched at the ESGP/FM conference in London in 2002. ${ }^{22}$ In its preamble the European definition of family medicine describes family medicine as an academic and scientific discipline with its own research content. The scientific approach is clearly described in the core competencies of family medicine. The challenge thus becomes, how is family medicine research going to explore this new way of doing business?

It is clear that the work will not be advanced by issuing yet another definition of family medicine but will be developed through the evolving research agenda of the discipline. The agenda should list the priorities for family medicine research in Europe and point to those issues that have not been adequately addressed.

Research Collaboration Within Family Medicine There are many examples of international research collaboration. They fall into 2 categories: (1) international development projects of family medicine through international agencies (Phare, World Bank, etc), as described under examples of national successes in Europe; and (2) academic development of the discipline created without external support, such as European General Practice Research Workshop (EGPRW) and the North American Primary Care Research Group (NAPCRG).

\section{European General Practice Research Workshop}

Research networks are an important element in fostering family medicine research. ${ }^{17,23}$ In 1974 EGPRW was established as a starting point for the development of family medicine research in Europe. ${ }^{24}$ Although individual research projects had been undertaken before then, this organization has added a new dimension to family medicine research. The aim of the workshop is to promote research in countries where research is not well developed and to foster international collaborative studies in family medicine. Not only has EGPRW managed to coordinate several international collaborative studies on topics relevant to practice, ${ }^{25,26}$ it has also accomplished much to educate researchers through its research courses. Currently, its main functions are to help young researchers develop their research ideas and to serve as a forum for exchange of expertise at the international level. The group meets twice a year and has established itself firmly as the key networking organization of family medicine research in Europe. 
North American Primary Care Research Group NAPCRG was established in North America in 1972. In addition to the academic departments of the American Academy of Family Physicians and College of Family Physicians of Canada, NAPCRG has consistently nurtured research in family medicine. NAPCRG is a binational organization whose mandate is to offer leadership and provide an exciting and constructive annual meeting. Its doubling of members during the past 3 years and its increasingly international character attest to its success. Two interest groups have had particularly strong influence: the Capacity Building Committee and the Participatory Research Group.

\section{Developing Our Own Success Criteria}

Development of family medicine journals is an essential step in establishing family medicine as an academic discipline. The existing academic standard of judging the quality of research only through indexing criteria, however, should be challenged on grounds of relevance for family medicine. New criteria for academic excellence should be developed that are more suitable for the purposes of the discipline.

\section{EXAMPLES OF NATIONAL SUCCESSES IN EUROPE}

The European practice research landscape lacks homogeneity. There is a long tradition of research in United Kingdom, ${ }^{27}$ the Scandinavian countries, and the Netherlands. In recent years, there are exciting developments in France ${ }^{28}$ and southern European countries, ${ }^{29}$ where first textbooks of family medicine research are starting to appear. ${ }^{30}$ To study the strategies for successful development of family medicine research, however, the countries that have recently gone through rapid changes are probably more illustrative than the ones that have already succeeded in developing a research base for the discipline.

Many exciting events have occurred in eastern Europe in the last 10 to 15 years. New democracies have emerged. Some health care systems, which have been based on the old Soviet model of primary health care, had to rediscover family medicine as a discipline. ${ }^{31}$ The countries in eastern Europe have taken different approaches to developing academic family medicine, and success has been variable. One successful example is Estonia, which used resources available through the World Bank project and partnered with neighboring Finland to establish academic family medicine solidly in a country where only a few years ago family medicine was not considered a discipline, let alone a scientific one. ${ }^{32}$

The case of Slovenia is different. Family medicine has been recognized as a specialty for a long time in Slovenia, but the training has been under the supervision of public health specialists. After independence, Slovenian family physicians came in contact with international organizations of family medicine research in Europe (EGPRW). Through cooperation at their meetings and without any formal family medicine development project, they developed their own research projects that have been successful at the national level. A result has been the creation of an independent department of family medicine at the university ${ }^{33}$ and the establishment of a family medicine research team that is regularly successful in obtaining national and international grants for research projects.

After the tragedy in Bosnia and Herzegovina, a project of developing family medicine has been introduced through cooperation with Canadian universities. The project has been successful not only in establishing vocational training for family physicians, but also in developing a research mentality for future family doctors by introducing an obligatory research module in the vocational training scheme.

\section{THE ROLE OF WORLD ORGANIZATION OF FAMILY DOCTORS (WONCA)}

Wonca plays an important role in advocating family medicine research through contacts with policy makers at the global level, and it has established a working plan for the development of research globally. The action plan, which was first discussed in Kuching, China, can be summarized by the following action points:

Action point 1: Wonca must make research a priority objective and take responsibility of the development of a research structure around the world.

Action point 2: Wonca defines a research agenda for practice.*

Action point 3: Wonca develops a strategy to promote research expertise in practice.

Action point 4: Wonca promotes research in practice in every medical school.

Action point 5: Wonca promotes that (inter)national medical research programs must include the domain of illness and disease in practice.

Action point 6: Wonca supports a practice-based research network that includes all countries around the world, including forums, journals, and conferences.

Action point 7: Wonca approaches Index Medicus for a change of policy in which "practice" will become a specialty heading and more specialty journals will be included.

*This is probably the only action point that needs to be reconsidered. Several attempts to create research agendas have ended up with similar lists. Probably Wonca should refine existing research agendas, making them relevant for world practice. 


\section{CONCLUSION}

Promotion of research in practice is vital because it contributes directly to Wonca's mission: improving health of the people around the world by promoting primary care. Despite the many obstacles listed in this article (including the lack of proper research training), there are strategies for success, and the overall trend of development is positive. The methods of how different countries have managed to develop family medicine research vary, but they usually include a combination of international support, local enthusiasm, willingness to change, and some luck. Although it is possible to give some guidelines how to improve the situation, ${ }^{34}$ the success often depends on local conditions.

To read or post commentaries in response to this article, see it online at http://www.annfammed.org/cgi/content/full/2/suppl_2/S30.

Key words: Research; family practice; family medicine; world health; international agencies; international cooperation

A version of this paper was presented at the Wonca Research Conference, Kingston, Ontario, Canada, March 8-11, 2003.

Acknowledgments: Chris van Weel, Moira Stewart, Peter Mac Isaac, and Adam Windak helped in the preparation of this paper.

\section{References}

1. Starfield B. Is primary care essential? Lancet. 1994;344:1129-1133.

2. Boland, M, Boelen, C, Fabb, W, Rivo, M, Sjonell, G, and Higgins, RW. Making medical practice and education more relevant to people's needs: the contribution of the family doctor. Rivo, M and Heck, JE. 1-102. 1999. Geneva, WHO.

3. van Weel C. General practice: a suitable place for clinical research. Eur J Gen Pract. 1995;1:6-7.

4. van Weel C. International research and the discipline of family medicine. Eur J Gen Pract. 1999;5:110-115.

5. Starfield B. A framework for primary care research. J Fam Pract. 1996;42:181-185

6. Huygen FJA. Family Medicine: The Life History of Families. New York, NY: Brunne/Mazel; 1982.

7. Plsek PE, Greenhalgh T. Complexity science: The challenge of complexity in health care. BMJ. 2001;323:625-628.

8. Norton PG, Stewart M, Bass MJ, Dunn EV, Tudiver F. Primary Care Research - Traditional and Innovative Approaches. Newbury Park, Canada: Sage Publications; 1991. Research Methods in Primary Care; vol 1

9. Stewart M. Tools for Primary Care Research. Newbury Park, Canada: Sage Publications; 1992. Research Methods in Primary Care; vol 2.

10. Tudiver F, Bass MJ, Dunn EV, Norton PG, Stewart M. Assessing Interventions. Traditional and Innovative Methods. Newbury Park, Canada: Sage Publications; 1992. Research Methods in Primary Care; vol 4.
11. Bass MJ, Dunn EV, Norton PG, Stewart M, Tudiver F. Conducting Research in the Practice Setting. Newbury Park, Canada: Sage Publications, 1993. Research Methods in Primary Care; vol 5.

12. Dunn EV, Norton PG, Stewart M, Tudiver F, Bass MJ. Disseminating Research / Changing Practice. Thousand Oaks, Calif: Sage Publications; 1994. Research Methods in Primary Care; vol 6.

13. Maijman F, deMelker RA. The extent of inter-and intrareviewer agreement on the classification and assessment of designs of singlepractice research. Fam Pract. 1995;12:93-97.

14. Britten N, Jones R, Murphy E, Stacy R. Qualitative research methods in general practice and primary care. Fam Pract. 1995;12:104-114.

15. Elder NC, Miller WL. Reading and evaluating qualitative research studies. J Fam Pract. 1995;41:279-285.

16. Kinmonth AL. Understanding and meaning in research and practice. Fam Pract. 1995;12:1-2.

17. Nutting PA. Practice-based research networks: building the infrastructure of primary care research. J Fam Pract. 1996;42:199-203.

18. Wallace $P$, Drage $S$, Jackson N. Linking education, research, and service in general practice. BMJ. 1998;316:323.

19. Mohanna K, Chambers R. Opportunities and options in general practice. BMJ. 2001;322:2.

20. Oldham J, Rutter I. Independence days. BMJ. 1999;318:748-749.

21. Oldham J. An inspectorate for the health service? BMJ.1997;315:896-7.

22. Allen J, Gay B, Crebolder H, Heyrman J, Švab I, Ram P. The European definition of general practice/family medicine. 2002. Available at: http://www.euract.org/pap041.html.

23. Green LA, Dovey SM. Practice based primary care research networks. BMJ. 2001;322:567-568.

24. Evans PR. Medicine in Europe: The Changing Scene in General Practice in Europe. BMJ. 1994;308:645-648.

25. COMAC-HSR in collaboration with the European General Practice Research Workshop. Crombie DL, Zee van der J, Backer P, eds. The Interface Study. Occasional Paper 48. London: Royal College of General Practitioners; 1990

26. Fleming DM. The European Study of Referrals from Primary to Secondary Care. Reported to the Concerted Action Committee of Health Services Research for the European Community. London: Royal College of General Practitioners; 1992

27. Thomas P, Griffiths F, Kai J, O'Dwyer A. Networks for research in primary health care. BMJ. 2001;322:588-590.

28. Levasseur G, Schweyer FX, Perriniaux J. Research in general practice in France today. Eur J Gen Pract. 2001;7:62-67.

29. deMaeseneer J, van Weel C. Research in general practice in Europe: a growing community. Eur J Gen Pract. 2001;7:90-91.

30. Masso G, Marchetto S. La Ricerca in Medicina di Famiglia. Milano: Passoni; 1995.

31. Švab I, Lember M. Regional profile: Central and Eastern Europe. In: Brown S, ed. Physician Funding and Health Care Systems - An International Perspective. London: The Royal College of General Practitioners; 1999: 54-62.

32. Kalda R, Maaroos H-I, Lember M. Motivation and satisfaction among Estonian family doctors working in different settings. Eur J Gen Pract. 2000;6:15-19.

33. Švab I, Yaphe $Y_{1}$ Correia de Sousa J, Passerini G. An international course for faculty development in Family Medicine: the Slovenian model. Med Educ. 1999;33:780-781.

34. Radda G. Primary care research: the MRC's proposals. Br J Gen Pract. 1998;48:872. 